\title{
Walter Pagel - Septuagenarius
}

\section{November 1968}

Fast sträubt sich unsere Feder, dieses Wort niederzuschreiben. Und seine lateinische Form mag die leider unleugbare Tatsache etwas verhüllen, daß unser hochverehrter Fachkollege und - wie ich mir herausnehme beizufügen - unser lieber Freund am 12. November die Schwelle des 70. Lebensjahres überschreitet. Der Auftrag, ihm diesen Glückwunsch auf den Geburtstagstisch zu lẻgen, hätte eine kompetentere Autorschaft erfordert. Doch sei mit einigen persönlich geprägten Worten versucht, der willkommenen Bitte zu entsprechen.

In seinem liebenswerten Nachruf auf unseren gemeinsamen Mentor Henry E. Sigerist, den führenden schweizerischen Historiker und Soziologen der Medizin jüngst verflossener Jahre, schreibt Pagel dem Verstorbenen einen «olympian success» zu. Dasselbe Epitheton drängt sich auch im Zusammenhang mit dem deutsch-englischen Gelehrten auf. Nur muß beigefügt werden, daß dessen Ruhm nicht auf demselben Fundament errichtet ist. Der große Gegensatz zwischen den beiden Persönlichkeiten liegt darin begründet, daß sich Pagels Leben in den vier Wänden von Studierzimmer und Sektionsraum abgespielt hat. Feder, Messer und Mikroskop waren Pagels Instrumente, während der Kosmopolit Sigerist durch die Überzeugungskraft seiner Sprache in der breiten Öffentlichkeit gewirkt hat. Man geht wohl nicht fehl in der Annahme, daß Pagels im Verborgenen gereiftes Werk teilweise zurückzuführen ist auf «das Pestjahr 1933» (wie er es nennt), das sein Lebensschifflein in so tragischer Weise aus der Bahn einer triumphalen akademischen Laufbahn geworfen hat.

Geboren als Sohn des bedeutenden Berliner Medizinhistorikers Julius LeOpoLd Pagel (1851-1912), muß der Jubilar, mit den Gaben des forschenden Denkers reich ausgestattet, schon früh sein Schaffen nach den beiden Polen von ebenso minutiösem literarischem und morphologischem Studium ausgerichtet haben. Die Ergebnisse dieser beiden Forschungsrichtungen scheinen methodisch auf zwei verschiedenen Ebenen zu liegen. Das analytisch-deduktive Vorgehen Pagels vermochte indessen aus zwei scheinbar heterogenen «Substraten» eine imponierende Einheit zu gestalten, deren einzelne Bausteine zu kennzeichnen erst aus größerer zeitlicher Distanz - wenn überhaupt - möglich sein wird.

Diesen Vorbehalt müssen wir anbringen, wird es doch kaum einen Gelehrten geben, der legitimiert genug sein wird, Pagels Beiträge zur pathologischen Anatomie und Pathophysiologie ebenso sachgemäß zu beurteilen wie die am Schreibtisch entstandenen profunden Studien zur Geschichte der Medizin.

Es ist nicht von ungefähr, daß Pagels erste große Leidenschaft den nach dem Ersten Weltkrieg so überaus bedrängenden Problemen der Tuberkuloseforschung galt. Nicht nur bewegte er sich als geborener Berliner dabei auf den Fußstapfen 
von Roвert Косн, des Entdeckers des Erregers dieser damals in Norddeutschland besonders grassierenden Krankheit, sondern die Heilstätten jener Region boten auch die praktischen Gelegenheiten, sich mit den komplexen, in der Lunge sich abspielenden Prozessen zu beschäftigen. War doch auch die Sanatoriumstradition im preußischen Flachland beheimatet.

Der Zürcher Pathologe Erwin Uehuinger hat Pagels große Verdienste um die immunbiologische Begründung der Tuberkuloselehre im Anschluß an KarL ERnst Ranke (1870-1926) anläßlich des 65. Geburtstages von Walter Pagel in der Deutschen medizinischen Wissenschaft prägnant gewürdigt und auch hingewiesen auf die wertvolle Ausgabe von Rankes Ausgewählte Schriften zur Tuberkulosepathologie, welche W. und M. Pagel in pietätvoller Weise besorgten. Wir dürfen aus der historischen Sicht der letzten Jahre beifügen, daß Pagels schon vor mehreren Jahrzehnten gewonnene Erkenntnisse sich auf andere Gebiete der allgemeinen Pathologie ausgeweitet haben.

Im Jahre 1960 hat Pagel zur Deutsch-englische medizinische Rundschau eine medikohistorische Übersicht über die «Geschichte deutsch-englischer Beziehungen in der Medizin » beigesteuert, die wir aus verschiedenen Gründen hier herausgreifen. Zuerst der persönlich-biographische Aspekt: Nach der Machtergreifung durch Hitler und seine Verbrecher-Clique fand Pagel in England eine neue Heimat. Und wer ihn, unermüdlich umsorgt von seiner ebenso feinsinnigen und von kulturellen Interessen erfüllten Gattin Magda, in seinem stillen Hause inmitten der grünen Gärten nördlich von London kennenlernen durfte, der weiß, wie sehr ihm die große Insel zur zweiten Heimat geworden ist. Hier fand sich auch für seine pathologisch-anatomische Forschung die adäquate, von der hohen Anerkennung der britischen Fachkollegen zeugende Arbeitsstätte.

Der schon früh zu hohen Ansprüchen berechtigende Schüler von Alexander Schmincke (1877-1953), dem er 1928 nach Heidelberg folgte, trug in hohem Maße dazu bei, daß die in Deutschland hochstehende Tuberkulose- und Allergieforschung auch im englischen Sprachgebiet Eingang fand.

Die von Pagel aufgeführten wissenschaftlichen Verbindungen und Beeinflussungen über den Ärmelkanal hinweg müßten also durch seine eigenen Leistungen ergänzt werden. Aber ein weiterer Grund ließ uns unter den Dutzenden von Arbeiten Pagels gerade zu diesem Aufsatz greifen. In schlichten Worten nennt er die beiden Wege, auf denen solche historisch-vergleichenden Ziele angestrebt werden können, nämlich den biographischen und den «bibliographischen Zugang» zum Gegenstand der Medizingeschichte. Und damit sind wir bei dem in den letzten Jahren je länger um so mehr in den Vordergrund tretenden Forschungsgebiet angelangt, dessen Beackerung der ideenreiche Gelehrte seinen schwachen körperlichen Kräften mit bewundernswerter Zähigkeit abgerungen hat.

Ähnlich wie in den Realwissenschaften bei Pagel mehrere Problemkreise im Mittelpunkt stehen, deren Lösung von den verschiedensten Seiten angestrebt wurde und in Hand- und Lehrbuchbeiträgen ihre Krönung fanden, so ist auch 